\title{
Family Burden in Opioid Dependence Syndrome in Tertiary Care Centre
}

\author{
Shyangwa PM, ${ }^{1}$ Tripathi BM, ${ }^{2}$ Lal R$^{2}$ \\ 'Department of psychiatry, BPKIHS, Dharan, Nepal, '2Department of Psychiatry, All India Institute of Medical Sciences, \\ New Delhi, India
}

\section{ABSTRACT}

This is a cross-sectional, hospital based study conducted in De-Addiction centre under department of psychiatry, AIIMS, New Delhi, India. Patients and their spouses fulfilling inclusion criteria were enrolled in the study after taking informed consent. A diagnosis of Opioid Dependence Syndrome (ODS) was made based on ICD-10 criteria and the assessment of severity of ODS was determined by Addiction Severity Index (Hindi version). Subsequently the family burden, perceived by spouses was assessed using Family Burden Interview Schedule (FBIS).

Most of the subjects were from urban or semi-urban areas, mostly from around the service facility. The maximum number of subjects was of age group 31-40 years with majority of having below high school level education. Both subjective and objective family burden was perceived as "severe" by subjects' spouses. The relationship between spouses' perceived burden and socio-demographic variables including duration of substance abuse were not correlated. Hence it was found that opioid dependent subjects cause considerable amount of distress to their care providers.

Key words: opioid dependence, family burden, severity of substance use, subjective and objective burden perception

\section{INTRODUCTION}

Substance abuse is widely prevalent, and no country or community is completely free from its problem. Substance abuse/dependence causes significant harm to self, family and society as a whole. Some of the harms are directly caused by substance used while others are due to the associated behavioral patterns, whose manifestation depends upon the complex substance -individual-society interaction. The burden caused by substance use is dependent on various factors and one of the most important factors is the severity of dependence. ${ }^{1}$ The term burden is defined and perceived differently by different people. For the research purpose, burden has been operationally defined as 'effects of subject upon family' on various areas, namely financial, family routine, family leisure, family interaction, and physical \& mental health of others. The financial burden, one of the major burden areas, is likely to be experienced by the families due to loss of patient's income and use up of funds to procure substances they are dependent upon. ${ }^{2}$ Substance abusers generally lack social skills and, thus have difficulties in engaging in appropriate and rewarding forms of interpersonal interactions which are necessary for satisfaction of human needs. ${ }^{3} \mathrm{~A}$ large number of the

\footnotetext{
Correspondence:

Dr. Pramod M. Shyangwa

Department of Psychiatry

BPKIHS, Dharan-18, Sunsari, Nepal.

Phone: +977-25-525555-3071(Res)/2347(Off)

Email: pshyangwa@yahoo.com
} 
relatives of substance users report physical violence towards themselves, unpredictable behavior, stealing, being lethargic and behaving in an embarrassing way in front of others. ${ }^{4}$

Substance users also exert negative effects on physical health of other family members. ${ }^{2}$ Bush et al reviewed prevalence of physical abuse and neglect in substance abusing families, and concluded that prevalence and magnitude of physical, sexual abuse and neglect in substance abusing families are common. The substance abusing individuals often have a disruptive effect on the mental health of other family members. Children in these families have increased risks for anxiety disorders, substance abuse and depression in adulthood. ${ }^{5}$

As the severity of dependence is the major factor of burden, several careful studies have been done on this issue. Solomon demonstrated that the severity of dependence affects various spheres of family life and gives rise various degrees of burdensome consequences. ${ }^{6}$ When family burden is concerned, most of the studies have examined the family as an etiological entity, where family process has typically been studied to examine the effect of the family on the subject's substance habit. ${ }^{7}$ However the burden on families on account of substance abuse by a family member has begun to come into focus since the 1990s and there is a dearth of comprehensive study on family burden resulting from substance use, particularly of opioid use in the literature. ${ }^{8}$ Thus, this study was embarked on to study the impact of substance abuse has on the family system, especially in the family of developing country where family tie is more cohesive and supportive in comparison to those in the west.

\section{MATERIAL AND METHODS}

This is a cross-sectional hospital based study conducted in De-Adiction centre under department of psychiatry, AlIMS, New Delhi, India. Subjects and their spouses fulfilling inclusion and exclusion criteria were included in the study after taking informed consent. A diagnosis of opioid Dependence Syndrome (ODS) was made based on ICD-10 criteria. Hindi version of Addiction Severity Index was administered to assess the severity of ODS. ${ }^{10}$ Subsequently subjects' spouses were administered Family Burden Interview Schedule. ${ }^{11}$ Interview was conducted after rapport was established.

Patients were recruited both from Inpatient and Outpatient departments of Drug Dependence Treatment centre, All India Institute of Medical Sciences, New Delhi. Subjects with opioid use and their spouses, who are staying with users, were screened for potential inclusion in the study, accordingly 50 cases of opioid dependent and their spouses were assessed.

Patient with the diagnosis of opioid dependence syndrome according to ICD-10 (WHO, 1992), ${ }^{9}$ age range of 20-45 years, married male. The patient with major chronic psychiatric illness: organic psychosis, schizophrenia, mental retardation, history of major psychiatric or chronic physical illness in the family and who did not give consent for participating in the study were excluded.

\section{Addiction Severity Index (ASI)}

The Hindi version of ASI adapted by department of psychiatry (AlIMS) was used for current study. This is a semi-structured, comprehensive, and clinical/research schedule designated to assess the multiple problems seen in drug and alcohol dependent persons seeking treatment. The assessing problem areas affected by substance abusers are as following:

1. Medical status

2. Employment / support status

3. Drug/alcohol use

4. Legal status

5. Family/social relationship

6. Psychological status

Two types of measures result from the collected data in each problem areas; severity (subjective) rating and composite (objective) scores.

Each item is rated on a 10-point scale where ' 0 ' denotes 'no need of treatment/help' and ' 9 ' denotes treatment/ help needed to intervene in life-threatening situation.

The permission for conducting this study was obtained from institutional research committee.

\section{RESULTS}

Most of the subjects in this study were from urban or semi-urban areas, mostly from and around Delhi. This study included married male subjects of 20-45 years age group. However the maximum number of subjects was of age group 31-40 years. Majority of the subjects had 'below high school level education' $(60.0 \%)$. Both subjective and objective family burden was perceived as "severe" by subjects' spouses. The relationship between spouses' perceived burden and sociodemographic variables including duration of substance abuse were not correlated.

Majority $(62.0 \%)$ of the patients was of age group 31 40 yrs. Majority $160.0 \%$ of the subjects had 'below high school level education' (Table 1).

Majority $(32.0 \%)$ spouses were of $31-35 \mathrm{yr}$. age. Majority $(64.0 \%)$ had below high school education (Table 3).

The relationship between spouses' perceived burden and socio-demographic variables including duration of substance abuse were not correlated by using Student's t-test (Table 7). 
Shyangwa et al. Family Burden in Opioid Dependence Syndrome in Tertiary Care Centre

Tables 1. Socio-demographic Profile

\begin{tabular}{lll}
\hline Age range (in years) & Frequency (n) & Percentage \\
\hline $20-25$ & 1 & 2.0 \\
$26-30$ & 12 & 24.0 \\
$31-35$ & 16 & 32.0 \\
$36-40$ & 15 & 30.0 \\
$41-45$ & 6 & 12.0 \\
Education level & & \\
Below high school & 30 & 60.0 \\
Completed high school & 15 & 30.0 \\
Higher education & 5 & 10.0 \\
Religion & & \\
Hindu & 40 & 80.0 \\
Sikh & 6 & 12.0 \\
Islam & 4 & 8.0 \\
Employment status & & 100 \\
Unemployed & 13 & 26.0 \\
Employed: & & 34.0 \\
Self-employed & 17 & 24.0 \\
Skilled & 12 & 16.0 \\
unskilled & 80 & 100 \\
Total & & \\
\hline & & \\
\hline & & \\
\hline
\end{tabular}

Table 2. Types of household structure

\begin{tabular}{lcc}
\hline Types & Frequency $(\mathbf{n})$ & Percentage \\
\hline Joint/extended & 26 & 52.0 \\
Nuclear & 24 & 48.0 \\
Domicile of subjects & & \\
Urban/suburban & 30 & 98.0 \\
Rural & 1 & 2.0 \\
Monthly Subjects earnings (in rupees) & \\
0-999 & 18 & 36.0 \\
$1000-2999$ & 20 & 40.0 \\
$3000-4999$ & 10 & 20.0 \\
$5000>$ & 2 & 4.0 \\
Monthly money expense(in rupees) & \\
$0-999$ & 14 & 28.0 \\
$1000-2999$ & 16 & 32.0 \\
$3000-4999$ & 14 & 28.0 \\
$5000>$ & 6 & 12.0 \\
Total & 50 & 100 \\
\hline Dutan & 14 & \\
\hline
\end{tabular}

Duration of marriage (in years) with Mean-12.78 (SD- 4.51)
Table 3. Spouses' socio-demographic profile

\begin{tabular}{lcc}
\hline Age range (in years) & Frequency (n) & Percentage \\
\hline $20-25$ & 8 & 16.0 \\
$26-30$ & 15 & 30.0 \\
$31-35$ & 16 & 32.0 \\
$36-40$ & 9 & 18.0 \\
$41-45$ & 2 & 4.0 \\
Education level & & \\
Below high school & 32 & 64.0 \\
Completed high school & 11 & 22.0 \\
Higher education & 7 & 14.0 \\
Employment status & & \\
House wife & 28 & 56.0 \\
Employed & 22 & 44.0 \\
Spouses' monthly earnings (in rupees) & \\
0-999 & 14 & 28.0 \\
$1000-2999$ & 9 & 18.0 \\
$3000-4999$ & & \\
$5000>$ & & \\
Total & $*$ & \\
\hline
\end{tabular}

Table 4. Family burden: Objective \& Subjective burden perceived by spouses $(n=50)$

\begin{tabular}{lcc}
\hline Objective burden & Frequency (n) & Percentage \\
\hline No burden (0) & 0 & 0 \\
Moderate (1-24) & 12 & 44.0 \\
Severe (25-48) & 28 & 56.0 \\
Total & 50 & 100 \\
Subjective burden & & \\
No burden (0) & 0 & 0 \\
Moderate (1-24) & 13 & 26.0 \\
Severe (25-48) & 37 & 74.0 \\
Total & 50 & 100 \\
\hline
\end{tabular}

Table 5. Family burden (Objective) perceived by spouses of Opioid Dependent Subjects in different problem areas $(n=50)$

\begin{tabular}{lcc}
\hline Burden areas & Mean & SD \\
\hline Financial burden (0-6-12) & 6.24 & 1.68 \\
Effects on family routines (0-5-10) & 16.0 & 2.34 \\
Effects on family leisure (0-4-8) & 14.0 & 1.97 \\
Effects on family interaction (0-5-10) & 6.0 & 2.33 \\
Effects on physical health ( 0-2-4) & 1.26 & 1.42 \\
Effects on mental health (0-2-4) & 2.00 & 0.89 \\
\hline
\end{tabular}


Shyangwa et al. Family Burden in Opioid Dependence Syndrome in Tertiary Care Centre

Table 6. Family burden (Objective) perceived by spouses of Opioid Dependent Subjects in different problem areas $(n=50)$

\begin{tabular}{|c|c|c|}
\hline Subjective burden & Mean & SD \\
\hline$(0-1-2)$ & 1.74 & 0.44 \\
\hline \multicolumn{3}{|c|}{ Degree of subjective burden } \\
\hline & Frequency (n) & Percentage \\
\hline Moderate ( up to 1 ) & 13 & 26.0 \\
\hline Severe burden $>1$ & 37 & 74.0 \\
\hline Total & 50 & 100 \\
\hline
\end{tabular}

\section{DISCUSSION}

This was a hospital based study on opioid dependent individuals registered in the Drug Dependence Treatment Centre (DDTC) in short: De-Addiction centre. Initial one to one interaction helped to establish rapport, then a formal interview with subjects and subsequently with their spouses was conducted. Almost always information was forthcoming, except for current legal status, and illegal activities. Although a bit evasive, fairly adequate information could be gathered on persuasion, even in these areas.

The study examined the burden perceived by spouses of opioid dependent subjects using the 'Family Burden Schedule ${ }^{\prime 11}$ and the relationship between family burden with severity of addition was assessed by using the 'Addition Severity Index'. ${ }^{10}$

Although the word 'severity' is frequently used term in the parlance of substance dependence, it has been defined in many ways; social complication withdrawal severity, quantity and frequency of use and inability to abstain. ${ }^{12-14}$ In this study the term severity implies as need for treatment (help) in multiple problems areas, as operationalized by authors of ASI $10 .{ }^{15}$ The problem areas include medical status, legal status, employment/support status, drug/alcohol use, family/ social relationship and psychological status.

\section{Socio-demographic profile}

The most of the subjects were from lower socioeconomic strata and urban setting, except one. This could either be due to the location of the facility within city or lack of awareness of availability of facilities to rural population or possibly burden perceived consequent to substance dependence may not be severe enough to warrant treatment. In contrast to the western studies where dependence is more common in broken homes, the majority of subjects in this study came from cohesive families. ${ }^{16}$

Likewise very few subjects had higher education, which may be explained by the fact that the subjects from lower socio-economic strata generally come to government run hospitals for their treatment where facilities are available free of cost.

Most of the subjects in this study earned less than Rs. 3000 ( $80 \$)$ per month and a large number of subject generated money from selling property, extorting money from family members and friends. Few of them were indulged in illegal activities, though they were not freely forthcoming. All these are in accordance with the literature from the West. ${ }^{4}$ The findings of this study also showed that the overall expenditure in the month to maintain his substance use habit was more than what the earning. The mean expenditure incurred to purchase the substance of abuse was calculated to be Rs. 2466 per month.

Table 7. Relationship between spouses' perceived family burden (total) and their socio-demographic variables $(n=50)$

\begin{tabular}{|c|c|c|c|c|c|}
\hline Variable & Categories & Mean & SD & P-Value & Significance \\
\hline \multirow[t]{2}{*}{ Age of spouse } & $20-30$ yrs. & 25.85 & 8.68 & 0.7971 & NS \\
\hline & $31-41$ yrs. & 25.26 & 7.23 & & \\
\hline \multirow[t]{2}{*}{ Education } & (0-5) Primary & 26.30 & +10.37 & 0.4589 & NS \\
\hline & $(6-12+2)$ high school + & 24.34 & +6.55 & & \\
\hline \multirow[t]{2}{*}{ Family structure } & Joint/extended & 25.76 & +8.45 & 0.8635 & NS \\
\hline & Nuclear & 25.37 & +7.59 & & \\
\hline \multirow[t]{2}{*}{ Duration of marries } & $0-10$ years & 25.76 & +8.45 & 0.7162 & NS \\
\hline & $11>$ years & 25.37 & +7.59 & & \\
\hline \multirow[t]{2}{*}{ Duration of substance use } & $0-10$ years & 25.76 & +8.35 & 0.8538 & NS \\
\hline & $11>$ years & 25.81 & +7.65 & & \\
\hline
\end{tabular}


Table 8. Severity of addiction (subjective) in subjects $(n=50)$

\begin{tabular}{lll}
\hline Domains & Mean & SD \\
\hline Medical status (0-9)* & 1.48 & +2.19 \\
Employment status (0-9) & 3.04 & 1.84 \\
Drug use (0-9) & 5.44 & 1697 \\
Legal status (0-9) & 0.74 & 1.61 \\
Family /social relationship ( 0-9) & 4.04 & 2.48 \\
Psychological status (0-9) & 1.10 & 1.25 \\
\hline
\end{tabular}

*Range:

0- No need of treatment/help

9- Treatment/ help is needed to intervene in lifethreatening situation

Table 9. Severity of addiction (composite/objective scores) in the subjects $(n=50)$

\begin{tabular}{lll}
\hline Domains ( range)* $^{*}$ & Mean & SD \\
\hline Medical status (0.0-1.0) & 0.262 & +0.31 \\
Employment status (0.0-1.0) & 0.641 & 0.20 \\
Drug use (0.0-1.0) & 0.264 & 0.10 \\
Legal status (0.0-1.0) & 0.071 & 0.14 \\
Family /social relationship (0.0-1.0) & 0.360 & 0.23 \\
Psychological status (0.0-1.0) & 0.100 & 0.13 \\
\hline
\end{tabular}

${ }^{*}$ Range:

0.0- No need of treatment/help

1.0 - Treatment/ help is needed to intervene in lifethreatening situation.
In this study majority of subjects $(62.0 \%)$ were of 31 40 years age group, whereas 26-30 year age group also consisted significant proportion (30.0\%). Western studies however show an increased prevalence of substance use among teenagers and adolescents. ${ }^{16,17}$

The mean duration of opioid use was 9.64 years (SD3.85), and most of them became dependent on opioid within a matter of month, which is comparable with the findings of study conducted by, where mean duration of heroin use was 9.2 years. ${ }^{17}$

\section{Subjective burden}

This study showed a strikingly high percentage $(74.0 \%)$ of spouses who had perceived severe burden due to their husband's opioid dependence, which is higher than burden consequent to chronic psychiatric and physical illness showed high burden. While studying family burden in paranoid versus non-paranoid schizophrenics observed that more than $50 \%$ of key relatives of both groups reported 'severe' burden. Gautam and Nijhawn in their study reported that $52.0 \%$ of relatives of chronic lung disease patients had perceived moderate burden, $44.0 \%$ had perceived severe burden, and only $4.0 \%$ perceived no burden. ${ }^{19-20}$ Opioid dependent individuals are likely to cause increased burden because schizophrenia patients are comparatively less troublesome for others, except during excitation phase, whereas opioid dependent individuals exhibit not only their deviant behavior under the influence of or during withdrawal, but they are more quarrelsome, demanding, incapable of managing money matter, stealing, selling properties leading to making life miserable.

Table 10. Relationship between Family burden (total) score and each problem areas of Addiction Severity Index (ASI), (subjective severity) $(n=50)$

\begin{tabular}{llllll}
\hline Problem domains & Coefficient & Standard Error & T P (2 Tail) & Significance \\
\hline Medical status & 1.416 & 0.4977 & 2.85 & 0.01 & $*$ \\
Employment status & 0.240 & 0.6035 & 0.40 & 0.69 & \\
Drug use & -0.064 & 0.6265 & -0.10 & 0.92 & \\
Legal status & -0.714 & 0.7228 & -0.10 & 0.92 & \\
Family /social relationship & 1.3693 & 0.4305 & 3.18 & 0.00 & $\dagger$ \\
Psychological status & -0.4809 & 0.8901 & -0.54 & 0.59 & \\
\hline
\end{tabular}

${ }^{*} \mathrm{P}=<0.05, \mathrm{tP}<0.001$

\begin{tabular}{lc}
\hline Problem domain & $\mathbf{R}^{\mathbf{2}}$ \\
\hline Medical status & $15.16 \%$ \\
Family/social relationship & $13.20 \%$ \\
Total of two problem areas & $28.36 \%$ \\
Total for all 6 domains & $29.20 \%$ \\
\hline
\end{tabular}

\section{Objective burden}

Opioid dependent subjects place objective burden on areas of: financial, effects on family routine, effects on family leisure, effects on family interaction, and effects on mental and physical health of others.

About $56.0 \%$ of spouse perceived 'objective burden' as severe which was less than subjective burden (76.0\%). This difference might be due to the structure of 
questionnaire, where subjective burden was assessed by only one question and that was basically related to emotional feeling, whereas objective burden was measured by more precise method i.e. adding score from multiple items (24 items).

\section{Financial Burden}

The majority of the subjects were unemployed and from low socio-economic strata indicating their financial hardship. Financial burden is likely to be experienced by the families due to loss of patient's income, especially when the individual happens to be the sole bread winner of the family.

\section{Effects on family routine}

Family rituals, such as daily meal time, festivals and celebration can be interrupted due to intoxication or apathetic behavior. ${ }^{22}$

In this study $54.0 \%$ of spouses had perceived moderate burden. Sequeira et al (1990) reported that $43.3 \%$ of mothers of severely handicapped children perceived severe burden on this sphere. ${ }^{23}$

Our study showed that $46.0 \%$ of spouses of opioid dependence felt severe and $54.0 \%$ moderate burden in terms of disruption of routine family activities.

By and large, the burden perceived by spouses of opioid dependent individuals was similar to burden perceived by key informants of severe mentally ill patients.

\section{Effects on family leisure}

The findings of the present study indicate that the burden caused by disruption of family leisure activities was higher (Mean 4.82, SD 1.43) compared to burden caused by chronic medical illness ( Mean 2.96, SD 1.47) and schizophrenia (Mean 3.8, SD 2.07).

\section{Effects on family interaction}

About $60.0 \%$ of spouses felt their husbands' habit as severely burdensome (Mean 5.90, SD 2.33), where range value was (0-5-10).Clinical literature often describes that the substance abusers lack social and communication skills, and have difficulties in engaging in appropriate and rewarding form of interpersonal interactions which are necessary for satisfaction of human needs. ${ }^{24}$

\section{Effect on physical health of others}

Fourteen percentage spouses had perceived severe, $54.0 \%$ moderate, and $30.0 \%$ perceived no burden, reflecting opioid dependence and other illness have similar low burdensome effects on others physical health. Burden on this domain has been found to be quite low in schizophrenia, bipolar affective disorder, and chronic medical illness. ${ }^{20}$

\section{Effect on mental health of others}

Majority $(64.0 \%)$ of spouses perceived moderate burden related to 'effects on mental health of others' and $36 \%$ felt severe burden, with mean score 2.00 , SD 0.89 . In the present study, out of six areas the majority of the subjects caused severe burden, i.e. $>50.0 \%$ of spouse perceived severe burden, except in the physical and mental health domain.

\section{Severity of substance dependence}

In this study, severity (subjective) rating showed 'drug use' as most impaired problem area whereas composite score method showed most impaired area as 'employment status'. Second most impaired problem area was "family/support relationship" in both scoring methods. Similarly least impaired domain in both scoring methods was legal status.

One reason for low employment score by composite score could be the culture specific questions, like do you have driver's license? This has low relevance in our society.

Although composite score shows that employment sphere was most severely impaired, the sociodemographic variables showed only $26.0 \%$ subjects were unemployed. This could be explained by the fact that "unemployment" was operationally defined as not having been working for last 6 month or more. In our study most of the subjects were self-employed, unskilled, laborers, daily wagers who could join their business as soon as they get treated and go back, so they in fact needed little help for their employment difficulties, reflecting in lower rater's (subjective) scoring.

\section{Severity of dependence and perceived burden}

Severity of opioid dependence is related to various variables like quantity and pattern of use, frequency of use, sex, and psychiatric condition in an individual.

The findings of this study demonstrated that family burden perceived by spouses was positively associated with 'medical status' and 'family/social relationship' domain of ASI of studied subjects. It was observed that these two domains influenced $28.0 \%$ of total family burden out of $29.0 \%$ and about $1.0 \%$ of total family burden was influenced by rest domain. Mortality and morbidity produced by substance abuse is a consequence of complex interaction involving wide range of factors, including pharmacological and toxicological properties of substances used, combination of substance used, route of administration and social support of substance users. ${ }^{25}$ 
However in this study most of the subjects had minimal severity in medical status domain. A few reported chest infection, pulmonary TB and abscess $18.0 \%$, cumulative).

Clinical and research literature often describes substance abusers as lacking social skills and their as having difficulties engaging in appropriate and rewarding form of interpersonal interactive which are necessary for satisfactory human relation. ${ }^{24}$

In the present study it was seen that there was a correlation between family relationship of $\mathrm{ASI}$ and family burden which could be explained by following facts: family interaction was the most burdensome domain, among all six problem domains in Family Burden Schedule in our study. And "Family/social relationship" domain stood second most impaired in both rater's (subjective) scoring and composite scoring.

\section{CONCLUSION}

Opioid dependent subjects cause considerable amount of distress to their care providers, i.e. spouses. A strong association between family relationship measured by ASI and family burden in spouses was evident.

\section{REFERENCE}

1. Marrison V, Plant M. Drug problems and pattern of service among illicit drug users in Edinburgh. British Journal of Addiction, 1990; 85: 547-52.

2. Bush M, Caronna FB, Spratt SE. substance abuse and family dynamics, in: Friedman L, Fleming NF, Roberts DH, Hyman (eds). Source book of substance abuse and addiction. Williams and Wilkins, Baltimore, 1996; 57-71.

3. O'Leavy MR, Donovan DM. Social skill acquisition and psychosocial development of alcoholics: a review addictive behaviour 1976; 1: 111-120

4. Velleman R, Bunnett G, Miller T, Orford J, Rigby K, Tod A. The families of problem drug abuser: a study of 50 close relatives. Addiction 1993; 85: 1281-9

5. Friedman AS, Granick S, Bansfield S, Kriesher C, Schwatz A. The consequences of drug use/abuse for vocational career: a longitudinal study of a male urban African Sample. American Journal of Drug and Alcohol Abuse 1996; 22(1): 57-73.

6. Solomon P, Draine J. Subjective burden among family members of mentally ill adults: relation to stress, coping and adaptation. American Journal of Orthopsychiatry 1995; 75 (3): 419-27.

7. Rosemary A, Webester MH. Peer and parental influences on adolescent's substance use: a path analysis. International Journal of Addiction 1994; 29:5.

8. Guidelines on harm reduction related to injecting drug use. International Federation of Red. Cross and Red Crescent Societies 2003; [cited 2006 Jun 4]. Available from: URL:http:/ / www.ifrccee.org/ERNA/hrguide

9. WHO. The ICD-10 Classification of mental and behavioral disorders: Guidelines, Geneva. 1992.

10. McLellan AT, Luborsy L, O’Brien CP, Woody GE. An improved evaluation instrument for substance abuse patients. The addiction severity index. Journal of Nervous and Mental Disorder, 1980, 168, 26-33.

11. Pai S, Kapur RL. The burden of the family of a psych iatric patient: development of an interview schedule. British Journal of Psychiatry 1981; 138, 332-5.

12. Selzer M. The Michigan Alcohol Screening Test: The quest for a new diagnostic instrument. Americal Journal od Psychiatry 1971;127:89-91.

13. Seller EM, Kalant H. Alcohol detoxification and withdrawal.
New England Journal of Medicine 976; 294: 757-762.

14. Cloninger CR. Neurogenetic adaptive mechanism in alcoholism. Science 1987;236: 410.

15. McLellan AT, Kushner H, Metzger D, Peters R, Smith I, Grissom G, Pettinati H, Argeriou M. The fifth edition of the Addiction Severity Index. Journal of Substance Abuse Treatment; 1992; 9: 199-213.

15. Jaffe J. H. Introduction and Overview Substance-Related Disorders. In: Sadock BJ and Sadock V A (eds). Comprehensive textbook of psychiatry. 7th ed. Lippincott Williams and Witkins 2005; 1; 924.

16. Sharma HK. Drug abuse consequences and responses: 2nd Indian drug country report. Draft report. Ministry of Health and Family welfare. Government of India. Nirmal Bhawan, New Delhi, 1995.

17. Prasad PS. Assessment of abuse liability of Nitrazepam among detoxified heroin dependent subjects. MD Thesis. All India Institute of Medical Sciences, New Delhi, 1996.

18. Dutta EK. Assessment of burden, coping and dependence in families of paranoid and non-paranoid schizophrenia. MD Thesis, All India Institute of Medical Sciences, New Delhi (1992).

19. Gautam S, Nijhawan M. Burden of families of schizophrenic and chronic lung disease patients. Indian Journal of Psychiatry 1986;28(2):156-159.

20. Baily HB, Haberman PW, Alksne H. Outcome of alcoholic marriages; endurance, termination of recovery. Quaterly Journals of Studies on Alcohol, 1962;23:610-23.

21. Bush M, Caronna FB, Spratt SE. substance abuse and family dynamics, in: Friedman L, Fleming NF, Roberts DH, Hyman (eds). Source book of substance abuse and addiction. Williams and Wilkins, Baltimore, 1996;57-71.

22. Sequeira EM, Rao DM, Subbakrishna D, Prabha GG. Perceived burden and coping styles of the mothers of mentally handicapped children. NIMHANS Journal 1990;8(1):63-67.

23. Beckett HD. Hypotheses Concerning the Etiology of Heroin Addiction in PG Bourne (Ed.). Addiction. New York: Academic Press;1974.

24. Gossop M. and Grant M. (eds). Preventing and controlling drug abuse. WHO, Geneva (1990). 